\title{
PENINGKATAN TATA KELOLA LAYANAN DI PERPUSTAKAAN UNIVERSITAS ISLAM NEGERI MATARAM
}

\author{
IMPROVEMENT OF SERVICE GOVERNANCE IN THE LIBRARY OF THE STATE ISLAMIC \\ UNIVERSITY OF MATARAM
}

\author{
1) Baiq Fitria Darmayani Putri, Ridwan, Rohana \\ 1.23) Universitas Muhammadiyah Mataram/D3 Perpustakaan \\ *Email: ridwanr320@gmail.com \\ *Email: rohana.mip@gmail.com
}

\begin{abstract}
ABSTRAK/ ABSTRACT
Perpustakaan di era saat ini harus melakukan perubahan dan peningkatan pelayanan kepada masyarakat. Keadaan ini yang mendorong para pustakawan, dan pelaku pemanfaatan informasi atau pengguna perpustakaan berusaha keras agar mendapatkan perkembangan informasi yang mutakhir dan dibutuhkan. Perpustakaan sebagai sumber informasi juga berperan penting dalam membangun karakteristik mahasiswa dalam mempelajari ilmu pendidikan. Perpustakaan sebagai sumber informasi dituntut untuk memberikan layanan informasi yang lengkap, cepat, jelas, dan tepat guna mendapat pertanggung jawaban sumbernya terutama pada lingkup perguruan tinggi sehingga diperlukannya pengabdian terkait kegiatan pelayanan di perpustakaan Universitas Islam Negeri Mataram. Target khusus yang diharapkan tercapai adalah perbaikan kualitas pelayanan melakukan kegiatan literasi dengan nyaman serta tidak lagi merasa segan untuk terus mengunjungi perpustakaan. Adapun metode yang digunakan untuk mencapai tujuan tersebut adalah dengan cara menghidupkan ulang perpustakaan. Semua tahapan kegiatan pengabdian masyarakat di UPT Perpustakaan Islam Negeri Mataram telah $100 \%$ dilaksanakan dan menghasilkan luaran diantaranya yaitu (1) Susunan penataan buku yang lebih teratur, (2) Kegiatan pelayanan teknis untuk mempermudah temu kembali informasi.
\end{abstract}

Kata Kunci : Pelayanan, perpustakaan, mahasiswa

Submited : 29 Oktober 2021

Revision : 1 November 2021

Accepted : 10 November 2021

$* * * *$

\section{A. PENDAHULUAN}

Perpustakaan di era saat ini harus melakukan perubahan dan peningkatan pelayanan kepada masyarakat. Hal tersebut berkaitan dengan perkembangan ilmu pengetahuan yang begitu cepat dan menyeluruh.Keadaan ini yang mendorong para pustakawan, dan pelaku pemanfaatan informasi atau pengguna perpustakaan berusaha keras agar mendapatkan perkembangan informasi yang mutakhir dan dibutuhkan. 
Perpustakaan dijadikan sebagai pusat sumber daya informasi serta menjadi jantung menuju suatu lembaga atau instansi, baik yang berkaitan dengan pendidikan, pembelajaran dan pelelitian. Perpustakaan juga dituntut untuk menyediakan segala macam informasi karena pemakainya banyak yang berada dikalangan akademis sehingga kebutuhannya akan informasi sangat akurat. Sejak awal perpustakaan didirikan sudah mempunyai tujuan, yakni mencerdaskan kehidupan bangsa dan menjadikan masyarakat yang berpendidikan lebih baik untuk dipercaya.

Perpustakaan juga sangat berperan penting dalam menumbuhkan minat baca pada masyarakat. Namun selain itu, orang tua juga memiliki peran yang penting dalam pendidikan anaknya dan harus bekerja sama dalam memperkenalkan perpustakaan sejak dini. Contohnya pada mahasiswa perkuliahan, ketika seorang mahasiswa memiliki niat membaca yang tinggi maka mereka akan sangat bersemangat untuk terus aktif dalam mengikuti perkuliahan. Oleh sebab itu, seorang pustakawan lebih berperan penting dalam mengajak para mahasiswa untuk datang dan membaca buku walau hanya beberapa menit saja, atau bisa dengan bantuan dosen yang memberikan tugas kepada mahasiswa yang berkaitan dengan perpustakaan.

Mahasiswa hanya datang ke perpustakaan bila ada tugas dari dosen dan buku yang dibaca hanya sebatas buku ajar saja. Aktivitas membaca mahasiswa mengalami penurunan dipengaruhi oleh teknologi informasi yang sudah sangat maju. Berbagai macam hiburan menjadi lebih menarik, sedangkan membaca membutuhkan perhatian khusus yang tidak dapat diselingi dengan aktivitas lain.

Perpustakaan sebagai sumber informasi juga berperan penting dalam membangun karakteristik mahasiswa dalam mempelajari ilmu pendidikan. Perpustakaan sebagai sumber informasi dituntut untuk memberikan layanan informasi yang lengkap, cepat, jelas, dan tepat guna mendapat pertanggung jawaban sumbernya terutama pada lingkup perguruan tinggi. Oleh karena itu, agar mahasiswa tetap memanfaatkan perpustakaan diperlukannya pengoptimalan pelayanan perpustakaan. 


\section{B. METODE}

Pelaksanaan kegiatan ini dilaksanakan di UPT Perpustakaan UIN Mataram terletak di kampus 2 UIN Mataram Jl. Gajah Mada No. 100 Jempong. Waktu pelaksanaan mulai tanggal 16 Maret 2021 hingga 30 April 2021. Metode yang digunakan dalam melakukan kegiatan ini dengan terjun langsung terlibat dalam kegiatan pelayanan di Perpustakaan Universitas Islam Negeri Mataram.

\section{HASIL DAN PEMBAHASAN}

Perpustakaan UIN Mataram telah berdiri dan telah bertrasformasi dengan Perguruan Tinggi Islam Negeri Mataram di Mataram, Nusa Tenggara Barat. Hingga tahun 2017, perpustakaan UIN Mataram mempunyai kekuatan 12 pustakawan dan 5 orang staf perpustakaan. 17 orang pegawai perpustakaan tersebut melayankan 25.931 judul buku dan 129.182 eks kepada 14.000 lebih civitas akademika UIN Mataram di kampus I, Perpustakaan FITK di Kampus 2, dan Perpustakaan Pascasarjana di Kampus 2.

Pada tahun 2018, terjadi pengembangan layanan yang signifikan yang dilakukan oleh manajemen Perpustakaan UIN Mataram. Selain mempunyai Kekuatan 12 pustakawan, dan 7 orang staf perpustakaan, serta dengan total jumlah koleksi \pm 26.000an judul, untuk melayani kebutuhan informasi 14.000an orang civitas akademika UIN Mataram, Perpustakaan menambah kekuatan koleksi dibidang digital. Pengembangan sistem informasi dengan memperkuat koleksi digital diawali dengan kegiatan studi banding ke Perpustakaan UIN Maulana Malik Ibrahim Malang, yang saat itu dikomandoi oleh bapak Fazudin Harlinsyah, MM. Tujuan dari kegiatan ini adalah untuk mengetahui kebijakan-kebijakan dan prosedur yang bermain pada tataran teknis manajemen Repository di perpustakaan UIN Maulana Malik Ibrahim Malang, serta mempelajari customisasi e-prints langsung dengan teknis IT Perpustakaan UIN Malang. Output dari kegiatan tersebut adalah:

1. Terbentuknya kebijakan berupa aturan dan prosedur yang meliputi teknis manajemen data maupun kebijakan yang bermain saat praktek "upload mandiri" karya ilmiah civitas akademika UIN Mataram. Hal ini sangat penting dalam 
menjamin keseragaman informasi bibliography untuk mendapatkan hasil mapping yang akurat yang menjadi deskripsi perkembangan keilmuan civitas akademika.

2. Proses customisasi e-prints dan ANZSRC yang baik. Proses customisasi ini penting agar tampilan repository dapat menjadi representasi lembaga dunia maya. Proses customisasi yang baik juga dapat menjadi promosi dan sosialisasi lembaga berupa data akurat tentang perkembangan scholarly communication di wilayah akademis UIN Mataram.

Selain dengan penguatan koleksi di bidang digital. Perpustakaan UIN Mataram juga menginisasi langganan Plagiarism Checker Turnitin sebagai bukti bahwa Perpustakaan sebagai lembaga pengelolaan informasi sangat concem di dalam peningkatan kualitas tugas akhir mahasiswa dan karya ilmiah tenaga pendidikan. Proses langganan yang diikuti dengan sosialisasi dan layanan software untuk seluruh civitas akademika kemudian digalakkan oleh Perpustakaan. Kegiatan sosialisasi dan layanan di back up oleh SK Rektor yang berfungsi sebagai regulasi yang bersifat sektoral untuk membantu usaha perpustakaan dalam meneguhkan peranan perpustakaan akademik untuk menekan tingkat plagiasi di UIN Mataram.

Pada tanggal 20 September 2018, terbit SK Rektor No. 1781 Tahun 2018 tentang Penetapan Pemberlakuan Wajib Simpan dan Upload Karya Ilmiah dan Kewajiban Melakukan Plagiarisme Cheker Atas Karya Ilmiah Sivitas Akademika UIN Mataram. Pada bulan Agustus 2020, Perpustakaan UIN Mataram pindah ke kampus 2 di Jl. Gajahmada No. 100 Jempong, bersama dengan keindahan seluruh 4 Fakultas lainnya (FDIK, FUSA, FS, dan FEBI). Karena itu, Perpustakaan FTIK kembali digabung ke Perpustakaan Pascasarjana di Kampus 1. Di Kampus 2 Fakultas dan kondisi Gedung Perpustakaan mengalami peningkatan yang signifikan. Dari semula hanya mempunyai luas $740 \mathrm{~m}^{2}$ (2 lantai), Perpustakaan kini menempati Gedung seluas $5600.19 \mathrm{~m}^{2}$ (3 lantai). Terdapat fasilitas baru di Gedung tersebut, seperti ruangan audio visual, ruang multimedia, ruang theater, ruang diskusi, dan ruang correl. Untuk menunjang aktivitas dan kreativitas mahasiswa, Gedung Perpustakaan juga dilengkapi dengan rooftop.

Begitu juga dengan kondisi SDM Perpustakaan yang mengalami kenaikan, baik dari segi kuantitas maupun kualitas. Secara kuantitas, perpustakaan menerima 3 calon pustakawan yang berlatar belakang Pendidikan S1 Perpustakaan. Dan dari segi 
kualitas, Perpustakaan UIN Mataram berhasil mensertifikasikan 9 orang pustakawan di tahun 2016 dan 2019, di 4 klaster yang berbeda, yaitu (klaster pengembangan koleksi, klaster literasi informasi dan promoasi perpustakaan, klaster pengolahan bahan perpustakaan).

Saat musim pandemic covid-19 merebak, UIN Mataram menerapkan kebijakan pembelajaran online (daring) penerapan Work From Home untuk seluruh tenaga pengajar, kecuali para pejabat dan pegawai. Kebijakan tersebut bertepatan dengan waktu pemindahan koleksi dari Perpustakaan dari Kampus 1 ke Kampus 2. Maka perpustakaan UIN Mataram berkonsertasi dalam mengubah layanan akademik yang dilakukan, dari manual ke full online, dan berkonsentrasi melakukan pencacahan dan stock opname koleksi diiringi dengan kegiatan weeding, serta konservasi dan preservasi koleksi. Kegiatan tersebut dilakukan dari rentang waktu 2020 sampai 2021.

Saat ini, Perpustakaan UIN Mataram masih terus berproses dalam memperkuat potensi diri, serta bebuat berbagai bentuk kekurangan menjadi potensi dan tantangan untuk selalu berubah dengan dinamis kearah yang lebih. Berubah dan terus tumbuh dan berkembang seiring dengan perkembangan UIN Mataram salah satuna engoptimalan layanan dalam bidang Perpustakaan agar dapat dimanfaatkan oleh mahasiswa.

\section{Layanan di Perpustakaan UIN Mataram}

Layanan yang diberikan oleh Perpustakaan UIN Mataram terdiri dari:

a. Layanan Baca Ditempat

Di ruangan baca bagi pemustaka disediakan beberapa ruangan diantaranya ruang baca refrensi, ruang baca tandon dan ruang baca sirkulasi, ruang baca Bi Corner, ruang baca sasambo. Ruang baca tersebut tersedia dalam bentuk lesehan dan terdapat bangku, meja dan layar televise di bagian sudut $\mathrm{Bi}$ Corner serta sofa sudut di masing-masing corner.

b. Sirkulasi

Kegiatan sirkulasi dilakukan secara otomasi dalam bentuk pinjam meminjam bahan pustaka yang disiapkan pihak pustakawan maksimal 3 buku yang memiliki jangka waktu 2 minggu dan apabila terjadi keterlambatan 
pengembalian diberlakukan sangsi berupa denda sesuai dengan ketentuan dari pihak perpustakaan.

\section{c. Refrensi Dan Tandon (Deposit)}

Layanan ini diberlakukan pihak perpustakaan bukan untuk dipinjamkan hanya ketersediaan baca ditempat dan dapat di photocopy oleh pemustaka.

d. Penelusuran

Penelusuran yang tersedia di UPT perpustakaan yaitu melalui OPAC (Open Public Acsess Catalog). Pemustaka dapat menelusur semua refrensi yang diinginkan pemustaka sesuai dengan kebutuhan di masing-masing jurusan dan fakultas yang ada di UIN Mataram atau civitas akademika secara mandiri dan bimbingan penelusuran dari pihak pegawai maupun pustakawan di UPT Perpustakaan UIN Mataram melalui 6 (Enam) unit computer yang tersedia di ruangan refrensi.

e. Layanan Literasi Informas

Layanan literasi informasi telah dilakukan melalui pengadaan kelas literasi yang diadakan pihak perpustakaan sesuai dengan jadwal yang telah ditentukan dan ada pula permintaan tersendiri dari masing-masing jurusan untuk diadakan kelas literasi khusus diluar jadwal yang telah ditetapkan pihak perpustakaan.

f. Layanan Turnitin Plagiarism Checker

Layanan ini dilakukan untuk memastikan bahwa tingkat plagiasi mahasiwa tidak melebihi dari aturan yang ditetapkan oleh Kementrian, yaitu $25 \%$ untuk S1, dan $20 \%$ untuk S2 dan S3.

\section{g. Layanan Peminjaman Sarana Untuk Berkegiatan}

Layanan ini diberikan untuk civitas akademka yang membutuhkan layanan untuk beraktifitas dalam menunjang kegiatan tri dharma perguruan tinggi.Layanan tersebut berupa layanan peminjaman ruang meeting, ruang correl, ruang diskusi, ruang audio visual, dan ruang multimedia.Pemanfaatan sarana dan prasarana perpustakaan diatur melalui prosedur khusus yang disesuaikan dengan ragam dan jenis kebutuhan dari civitas. 


\section{h. Layanan Repository}

Layanan ini dilakukan untuk membangun digital archive bagi tenaga pengajar (dosen) dan tenaga kependidikan di UIN Mataram.Layanan ini dilakukan sesuai waktu kerja pustakawan.

\section{Kegiatan Layanan di Perpustakaan UIN Mataram}

\section{a. Kegiatan Di Ruang Sirkulasi}

Menurut Bafadal-Ibrahim (2004:24) “pelayanan sirkulasi adalah kegiatan kerja yang berupa pemberian bantuan kepada pemakai perpustakaan dalam proses peminjaman dan pengembalian bahan pustaka".

Macam-macam kegiatan di layanan sirkulasi:

1) membuat peraturan mengenai pemakaian atau peminjaman koleksi.

2) Membuat pengumaman tentang pendaftaran anggota perpustakaan langsung tertulis diperpustakaan

3) Melakukan penagihan kepada para anggota perpustakaan yang belum melakukan peminjamannya, padahal sudah habis batas waktu peminjamannya dengan cara ditagih langsung ataupun lewat surat tagihan.

4) Mencatat dengan tertib dan teratur semua pemasukan uang pendaftaran anggota perpustakaan maupun perpustakaan maupun uang denda keterlambatan pengembalian koleksi pustaka, untuk kemudian meyetorkannya kepada yang berwenang ataupun pemimpin perpustakaan.

5) Melayani permintaan "Surat Bebas Pinjaman Pustaka (SBPP)" kepada para anggota perpustakaan yang memerlukan untuk kepentingan studi.

6) Adapun kegiatan penulis di ruang sirkulasi antara lain:

a) Pemasangan cip

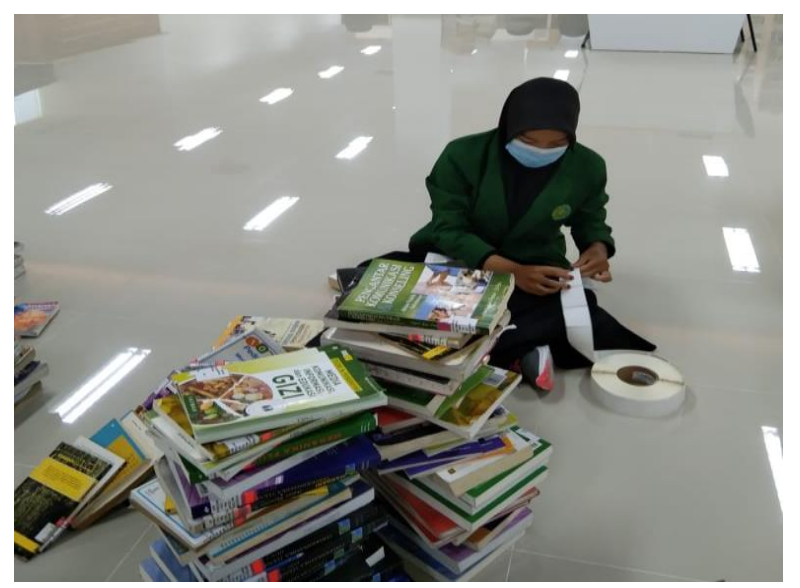


b) Memasukkan data ke chip melalui alat workstation

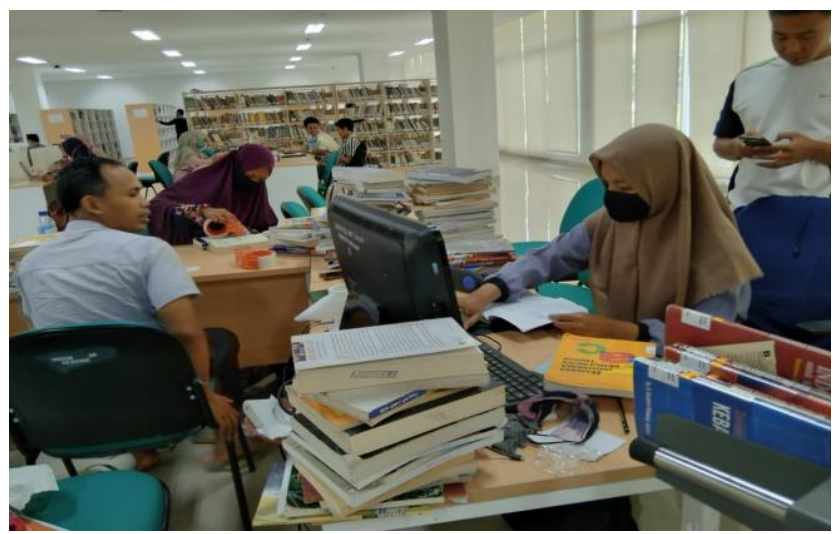

Di ruang sirkulasi, penulis diajarkan oleh petugas untuk memasang chip RFID (tagging) di buku. Pemasangan chip ini dimaksudkan agar buku yang akan dipinjam pemustaka tanpa melalui prosedur yang berlaku, akan menyebabkan alat RFID Gate akan berbunyi. Chip juga memungkinkan pemustaka untuk melakukan peminjaman mandiri (melalui self chek) dan pengembalian mandiri (melalui anjungan pengembalian mandiri). Untuk mengaktifkan chip pada buku, maka penulis diajarkan untuk memasukkan data ke chip melalui alat workstation. Cara memasukkan data tersebut adalah memasukan kode registrasi bibliografi buku ke aplikasi yang terhubung ke slims (sistem otomasi perpustakaan). Proses pembelajaran ini penulis terima dari petugas perpustakaan yaitu Pak Suaeb, Pak Solihun, Pak Sugito.

\section{Kegiatan di Ruang Pengolahan Bahan Pustaka}

Pengolahan bahan pustaka merupakan salah satu inti dari tugas perpustakaan. Bahan pustaka yang masuk ke perpustakaan wajib diolah dengan baik agar proses temu kembali informasi nantinya berjalan lancar dan mewujudkan tertib administrasi.

Kegiatan pokok dalam pengolahan bahan pustaka yaitu:

a. Inventarisasi

Kegiatan inventarisasi merupakan tindak lanjut setelah diteriamnya koleksi.Jadi, sesungguhnya kegiatan inventarisasi berkaitan langsung dengan pengadaan. 


\section{b. Klasifikasi}

Klasifikasi adalah pengelompokan yang sistematis dari pada sejumlah objek, gagasan, buku atau benda-benda lain ke dalam kelas atau golongan tertentu berdasarkan cirri-ciri yang sama.

\section{c. Katalogisasi}

Katalogisasi adalah proses pembuatan daftar pustaka (buku, majalah, $\mathrm{CD}$, film mikro dan sebagainya) milik suatu perpustakaan. Daftar ini berfungsi untuk mencatat koleksi yang dimiki, membantu proses temu kembali, dan mengembangkan sandar-standar bibliografi internasional

\section{d. Sherving}

Sherving adalah kegiatan penjajaran koleksi ke dalam rak atau tempat koleksi berdasarkan sistem tertentu.

Kegiatan penulis selama magang di ruang pengolahan antara lain

e. Stempel buku

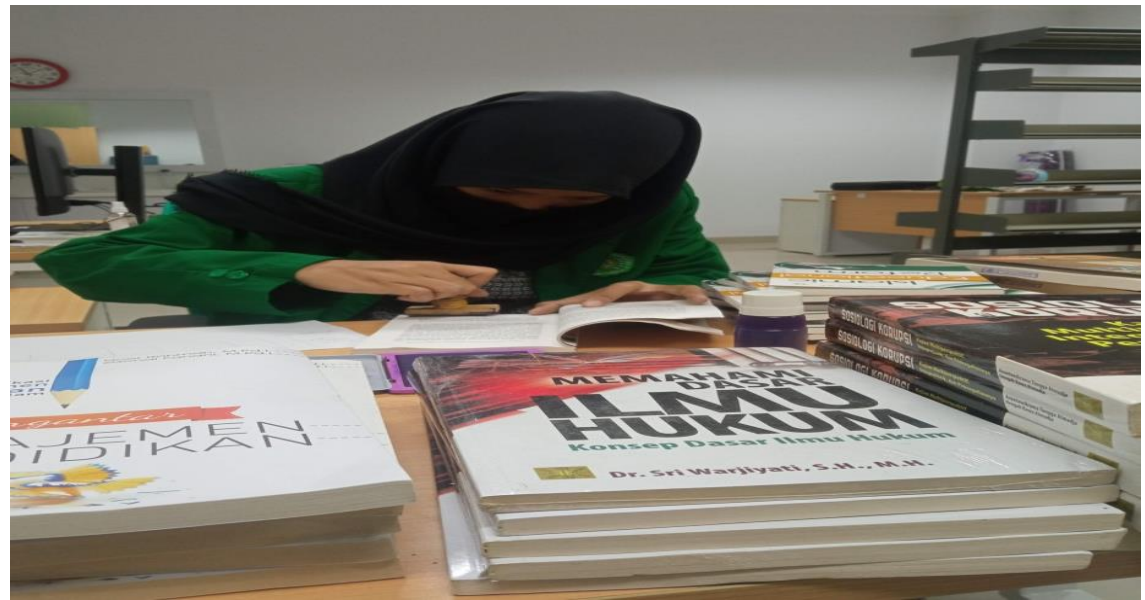

f. Klasifikasi buku

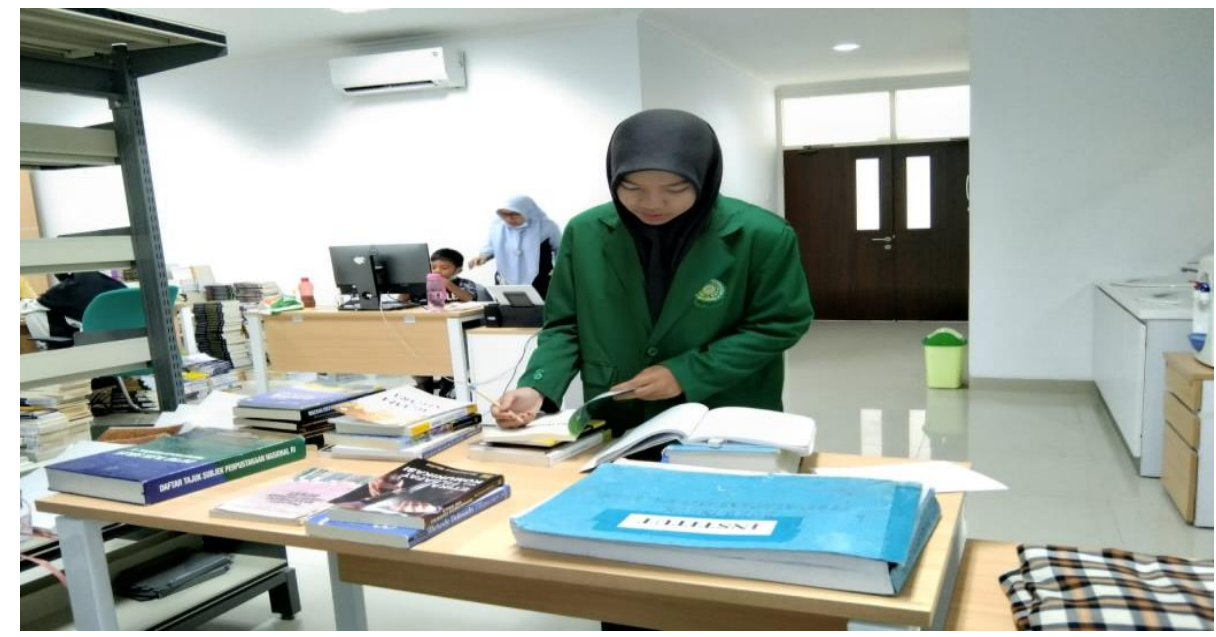


Di ruang pengolahan bahan pustaka penulis diajarkan oleh petugas untuk menstempel buku, membuat klasifikasi buku, membuat catalog, memberikan label buku serta mengimput data buku ke slims. Selain itu, penulis juga diajarkan cara untuk memasukan data buku ke repository UIN Mataram. Proses pembelajaran ini penulis terima dari petugas perpustakaan yaitu Ibu Yunita dan Ibu Eni.

\section{Kegiatan di Ruang Refrensi dan Ruang Tendon}

\section{a. Pengoprasian SLiMS}

Senayan Library Management System (SLiMS) adalah perangkat lunak sumber terbuka (open source) untuk sistem managemen perpustakaan (library management system) yang dikembangkan dan digunakan pertama kali oleh Perpustakaan Kemendikbud. Aplikasi berbasis web ini dibangun dengan menggunakan bahasa PHP dan basis data MySQL.

Berikut langkah-langkah menjalankan apliaksi SLiMS yang telah dipasang sebelumnya:

1) Jalankan file apache_start.bat dan maridb_start.bat yang terdapat pada folder slims yang telah kita pasang sebelumnya.

2) Jika muncul peringatan windows firewall, pilih opsi Allow Access agar kedua file tersebut diizinkan berjalan pada sistem oprasi windows anda.

3) Buka browser Mozilla Firefox atau Chrome, lalu ketikkan alamat localhost:8089pada kolom addres, jika berhasil akan muncul tampilan OPAC aplikasi SLiMS.

4) Untuk masuk ke dalam aplikasi, pilih menu humberger dengan tanda atau icon tanda baris tiga yang terletak disebelah kanan atas, lalu pilih Library Login.

5) Isikan username: admin serta password: admin lalu pilih login

6) Jika berhasil masuk, akan masuk ke dalam tampilan dashboard aplikasi. 
b. Menyunting data bibliografi dan eksemplar

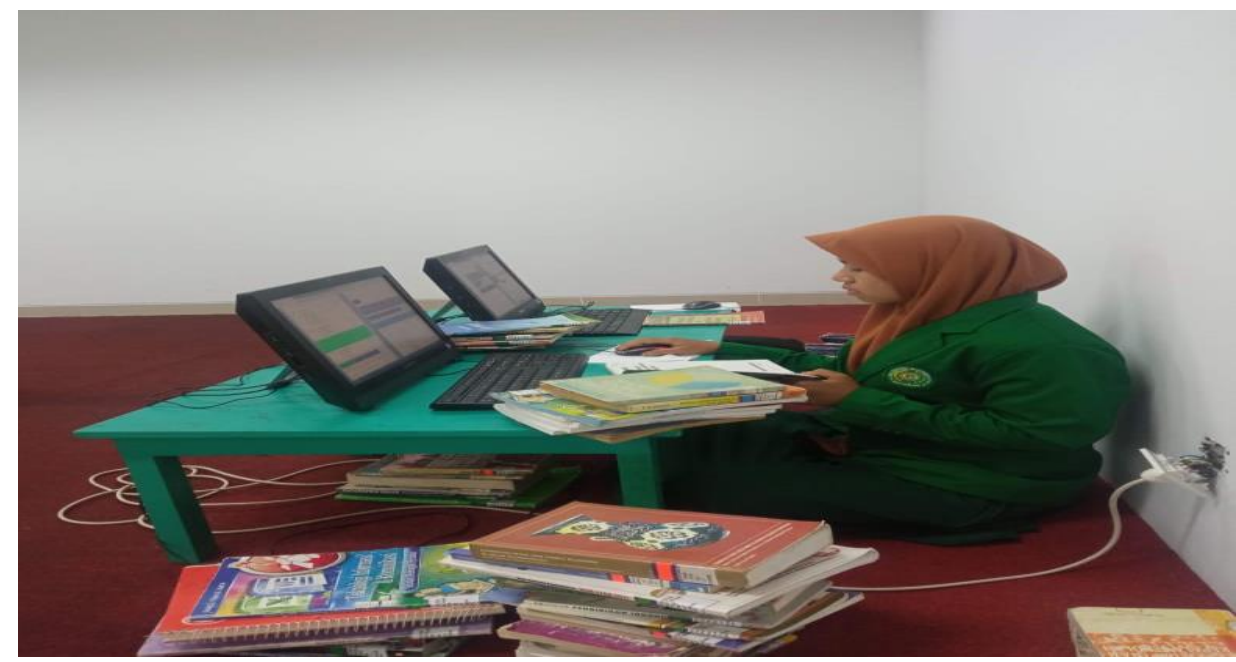

Bibliografi adalah pustaka yang mencangkup isi dan deskripsi sebuah buku yang disusun secara sistematik berupa daftar menurut aturan. Bedasarkan Anglo American Cataloguing Rules (AACR) ada delapan (8) area deskripsi bibliografi: Daerah judul dan pernyataan tanggung jawab, Daerah edisi, Derah data khusu, Derah penerbitan dan distribusi, Daerah seri, Daerah catatan, dan Derah nomer standar (ISBN dan ISSN).

Data item atau data eksemplar adalah jumlah dari koleksi yang mempunyai data bibliografi yang sama. Pada aplikasi slims jika koleksi sudah diisi data bibliografi tetapi belum menambahkan data item maka koleksi tersebut belum terlihat jumlahnya. Data item atau data eksemplar adalah jumlah dari data koleksi yang mempunyai data bibliografi yang sama.

Langkah-langkah menambah item atau eksemplar:

1) Klik menu bibliografi, kemudiandaftar bibliografi.

2) Pilih judul buku yang akan ditambahkan item kemudian klik sunting.

3) Kemudian klik sunting

4) Lalu klik tambah eksemplar baru

5) Lalu isi setiap kolom nomer eksemplar dapat menggunakan nomer induk atau bisa membuat nomer sendiri-sendiri dengan format, angka atau kombinasi angkai dari huruf contoh: B0001

6) Kode inventaris diisi dengan nomer inventaris sesuai dengan nomer inventaris, sesuai dengan nomer induk buku itu diterima contoh: 0001-2012

7) Lokasi rak diisi dengan tempat buku itu diletakan contoh rak 1 
8) Tipe koleksi diisi sesuai jenis koleksi

9) Status eksemplar diisi dengan status koleksi

10) No pemesanan, tanggal pesenan, tanggal penerimaan, agen sumber perolehan, fatur, tanggal fatur dan harga diisi jika koleksi tersebut melalui proses pembelian

11) Kemudian klik tanda silang $(\mathbf{X})$

12) Kemudia klik pembaharui

Ruang refrensi dan Ruang tandon, penulis diajarkan oleh petugas untuk menyunting data bibliografi dengan cara memperbaiki eksemplar buku yang salah. Penulis juga ditugaskan untuk membuat data bibliografi baru jika ada data buku yang belum masuk ke dalam sistem slims. Untuk itu, penulis dibuatkan akun slims pribadi oleh petugas. Proses pembelajaran ini penulis terima dari petugas perpustakaan yaitu Ibu Nurhasanah, Pak Wahyudi, Kak Rifki, dan Kak Ateja.

\section{Kegiatan di ruangan koleksi khusus dan konservasi}

\section{a. Penduan penelusuran koleksi skripsi online dan repository}

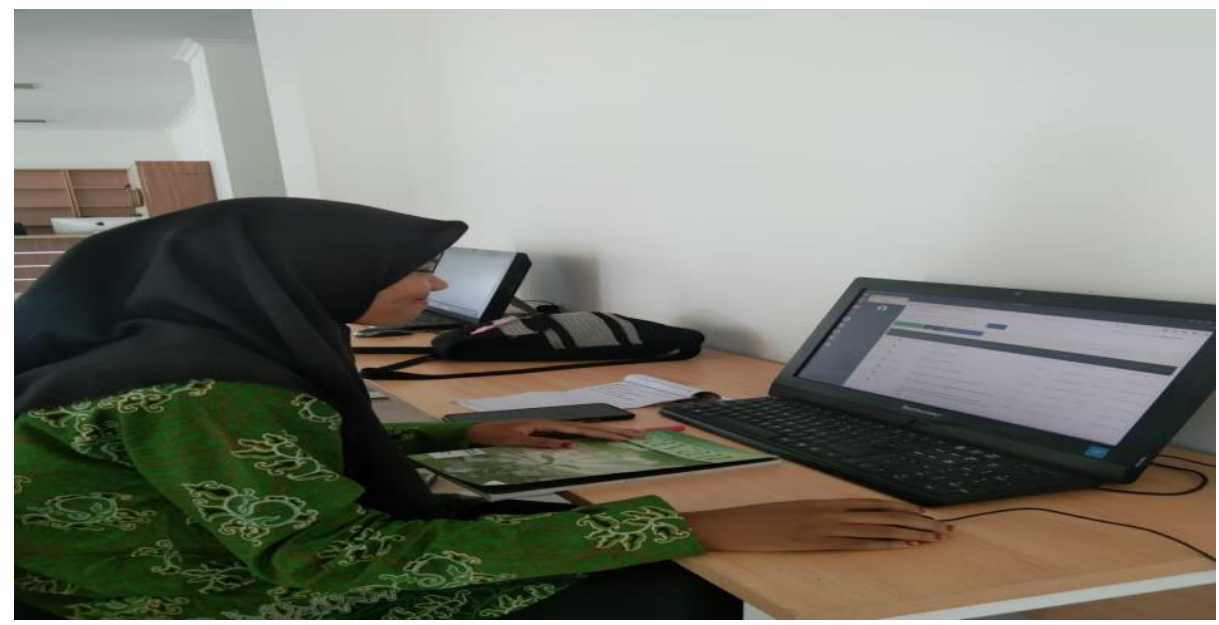

Koleksi skripsi, tesis dan desertasi online disebut sebagai koleksi e-theses merupakan koleksi-koleksi karya ilmiah yang dihasilkan oleh mahasiswamahasiswa yang tidak dipublikasikan secara resmi.

Repository adalah koleksi-koleksi karya ilmiah baik non karya ilmiah mahasiswa yang dihasilkan oleh dosen, karyawan dan civitas akademika yang lainnya baik sudah dipublikasikan di tempat lain atau dalam format lain, ataupun yang tidak dipublikasikan. 
Untuk menelusuri koleksi-koleksi yang ada di database tersebut, berikut langkah-langkah penelusurannya:

1) Masuk ke aplikasi etheses atau repository online di alamat link:

a) http://etheses.uinmataram.co.id/

b) http://repository.uinmataram.co.id/

2) Di beranda depan terdapat menu:

a) Simpel Search: Untuk pencarian koleksi secara cepat berdasarkan judul, pengarang atau tema yang dicari

b) Later Addition: berisi list koleksi-koleksi terbaru

c) Search Repository: menampilkan beberapa model pencarian koleksi

d) About This Repository: berisi tentang tentang informasi repository

e) Policy Repository: berisi tentang informasi aturan main dalam repository

3) Selain terdapat list tampilan dihalaman utama, dalam beranda terdapat menu-menu untuk melihat fasilitas dalam data base seperti:

a) Statistics: yang digunakan untuk melihat statistik pengguna koleksi

b) Browser: yaitu pilihan list koleksi berdasarkan tahun koleksi, subjek yang dibahas, devisionis (fakultas, jurusan, dan unit) dan pengarang koleksi.

\section{b. Pelestarian bahan pustaka}

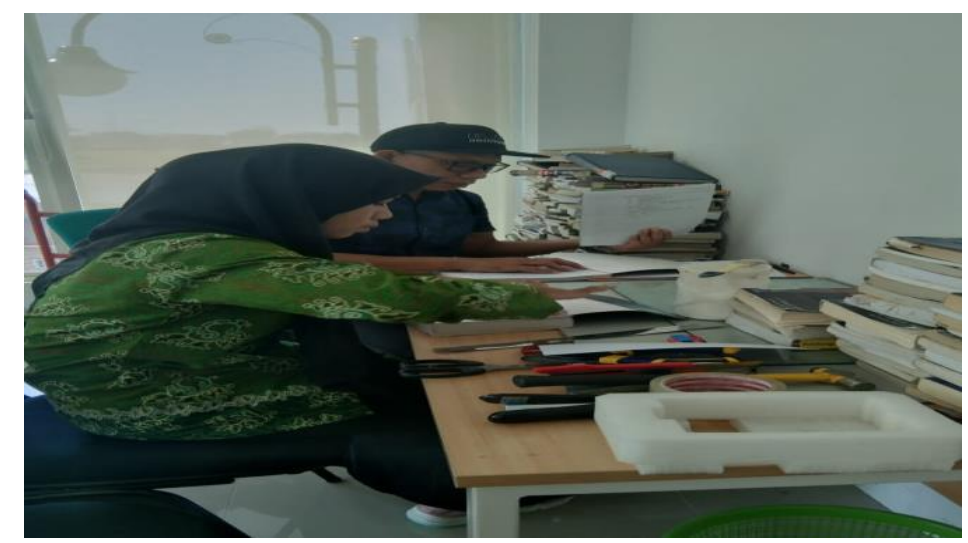

Pelestarian atau konservasi bahan pustaka sangat diperlukan untuk mengantisipasi dan mencegah kerusakan bahan pustaka. Konservasi menurut Kamus Besar Bahasa Indoonesia, (2002:589) adalah upaya pengawetan, pemeliharaan penjagaan, dan pelindungan, sedangkan konservasi mempunyai makna sebagai pemeliharaan dan perlindungan sesuatu secara teratur untuk 
mencegah kerusakan dan kemusnahan dengan jalan mengawetkan, pengawetan, dan pelestarian.

Penyebab kerusakan:

a. Faktor fisik

b. Faktor kimia

c. Faktor biota

d. Faktor bahan

e. Faktor manusia

Diruangan koleksi khusus dan konservasi, penulis diajarkan oleh petugas untuk mencari skripsi yang dibutuhkan oleh mahasiswa lewat etheses UIN Mataram. Penulis juga diajarkan cara untuk memperbaiki buku yang sudah rusak (robek) halamannya. Proses pembelajaran ini penulis terima dari petugas perpustakaan yaitu Pak Alimudin dan Pak Hamam.

\section{SIMPULAN}

Berdasarkan hasil kegiatan layanan perpustakaan yang dilakukan yaitu layanan yang diberikan Perpustakaan UIN Mataram adalah layanan baca ditempat, sirkulasi, refrensi, tandon (deposit), penelusuran berbagai sumber informasi, layanan turnitin plagiarism checker, layanan peminjaman sarana untuk berkegiatan, layanan repository, layanan bebas pustaka, dan layanan penyerahan tugas akhir. Seluruh layanan disediakan di UPT Perpustakaan UIN Mataram sudah terotomasi, mulai dari scan kartu pengunjung, sistem pencarian bahan pustaka lewat OPAC (Online Public Access Catalogue), peminjaman bahan pustaka sampai dengan mencari skripsi lewat etheses Peran pustakawan sangat penting dalam melayani kebutuhan akademik mahasiswa UIN Mataram. 


\section{DAFTAR PUSTAKA}

Soedibyo, Noerhayati. (1987). Pengelolaan Perpustakaan, Bandung: Alumni

Undang-undang No. 43 Tahun 2007 Tentang Perpustakan. Jakarta: Perpustakaan Nasional RI. 2007.

Suwarno, Wiji. (2014). Ilmu Perpustakaan dan Kode Etik Pustakawan, Yogyakarta: ARRUZZ MEDIA 